Research Article

\title{
Coupled Static-Dynamic Tensile Mechanical Properties and Energy Dissipation Characteristic of Limestone Specimen in SHPB Tests
}

\author{
Qi Ping $\mathbb{D}^{1,2,3}$ Zhaohui Fang, ${ }^{1,2,3}$ Dongdong Ma ${ }^{10},{ }^{1,2,3}$ and Hao Zhang ${ }^{1,2,3}$ \\ ${ }^{1}$ State Key Laboratory of Mining Response and Disaster Prevention and Control in Deep Coal Mine, \\ Anhui University of Science and Technology, Huainan, Anhui 232001, China \\ ${ }^{2}$ Research Center of Mine Underground Engineering, Ministry of Education, Huainan, Anhui 232001, China \\ ${ }^{3}$ Anhui University of Science and Technology, Huainan, Anhui 232001, China
}

Correspondence should be addressed to Dongdong Ma; dongdonm@126.com

Received 28 May 2019; Revised 21 August 2019; Accepted 6 November 2019; Published 11 February 2020

Academic Editor: Flavio Stochino

Copyright (C) 2020 Qi Ping et al. This is an open access article distributed under the Creative Commons Attribution License, which permits unrestricted use, distribution, and reproduction in any medium, provided the original work is properly cited.

\begin{abstract}
To investigate the dynamic splitting tensile mechanical property of limestone under coupled static and dynamic state, the dynamic split tensile tests of limestone under one-dimensional coupled static and dynamic load with different strain rates were performed with the help of modified split Hopkinson pressure bar (SHPB) equipment. The dynamic splitting tensile mechanical property and energy dissipation characteristic under two stress states were also compared in this research. Test results indicated that the dynamic tensile strength of the limestone specimen increased with the increase of average strain rate, exhibiting an obvious strain rate effect. In addition, dynamic tensile strength under uniaxial state was higher than that under one-dimensional coupled static and dynamic load state under the same test condition. Moreover, the deformation modulus increased with increasing average strain rate under uniaxial state, while it decreased with increasing average strain rate under coupled static and dynamic state. Both the reflected energy and absorbed energy linearly increased with increasing incident energy. The preload in the radial direction could increase the reflected energy and decrease the absorbed energy. Moreover, the transmitted energy with preload state was slightly lower than that under uniaxial state. Finally, the dynamic tensile strength of limestone specimen increased as a power function with increasing absorbed energy.
\end{abstract}

\section{Introduction}

Tensile strength of rock was an important parameter in geotechnical engineering design [1], which was much lower than its compressive strength. Tensile failure was a main failure mode of rock and had been observed in many rock engineering [2]. Therefore, it was necessary to study the tensile properties (e.g., strength and deformation) of rock under different test conditions [3]. As a typical brittle material, Brazilian disc test was the most common test method to obtain the tensile mechanical property of rock materials, which had been recommended by the international society of rock mechanics (ISRM) [4-6]. By summarizing previous theoretical and experimental investigations, it could be found that the tensile property of rock under static to quasi-static strain rates had acquired abundant achievements [7-9]. However, studies on dynamic tensile property of rock were relatively insufficient compared with that under static and quasi-static loads. Moreover, test results under static and quasi-static loads could not be applied to evaluate the deformation failure characteristic of rock under dynamic loading because of the rate effect of materials [10]. Investigations showed that the mechanical response of rock materials under dynamic load were obviously different compared with that under static load $[11,12]$.

Split Hopkinson pressure bar (SHPB) equipment has become the most effective device to test the dynamic tensile strength and deformation properties of rock at high strain rates [13-16]. In recent years, researchers have shown an 
increased interest in dynamic tensile tests on rock, which have acquired plenty of achievements [17-26]. The main representative study results were as follows: Gong and Luo $[17,18]$ used four test methods to compare the tensile strength of sandstone under different loading rates $\left(10^{-2} \mathrm{MPa} / \mathrm{s}\right.$ to $\left.10^{0} \mathrm{MPa} / \mathrm{s}\right)$, and the test results indicate that the tensile strength of sandstone specimen increases with increase in the logarithm of loading rate. Ai et al. [19] analyzed the dynamic fracture properties, crack propagation law of rock with different impact loading rates using experiments, and numerical simulation approach. Considering the stress state of rock in engineering projects, Wu et al. [20] performed the dynamic tensile experiments to investigate the effect of pretension on the dynamic tensile strength of rock, and study results indicate that the dynamic tensile strength decreases with increasing loading rates. Deng et al. [21] proposed an energy consumption model based on fractal rock mechanics and fracture mechanics theory. Moreover, the relationship between energy consumption and rock fragment size distribution was studied. Dai et al. [22] analytically and experimentally studied the flexural strength of Barre granite under a wide range of loading rates using a newly proposed semicircular bend test. Test results indicated that an obvious strain rate effect was found for the flexural tensile strength anisotropy features.

The theoretical and experimental studies on tensile mechanical behavior of rock cited above primarily concentrated on the dynamic strength of rock under uniaxial state. However, there had been little research on the energy dissipation characteristic of rock under coupled staticdynamic states in the SHPB split tensile test. Therefore, in this paper, the dynamic splitting tensile tests of limestone specimen were performed by using modified SHPB device, and the dynamic splitting tensile mechanical properties and energy dissipation characteristic under two stress states (uniaxial and coupled static-dynamic states) with different strain rates were compared in this research. Moreover, the effects of preloading in the radial direction and strain rate on dynamic splitting tensile load-displacement curves, peak stress, deformation modulus, failure mode, and energy dissipation were also investigated. The study results could provide basic theory references for the stability analysis of surrounding rock in blasting excavation process.

\section{SHPB Splitting Test Principle of Disc Specimen}

2.1. Specimen Machining and Static Physical-Mechanical Parameters. The test limestone specimens were collected from Shungeng Mountain in Huainan city, Anhui province. Limestones with better integrity and homogeneity were selected as test specimens to reduce data dispersion. Rock specimens were processed according to the rock mechanics test procedures. The coring, cutting, and polishing processes were carried out using a ZS-100 pattern drilling machine, DQ-4 pattern cutting machine, and SHM-200 pattern double ended polishing machine. The size of prepared specimens was $\Phi 25 \times 50 \mathrm{~mm}$. The basic physical and mechanical parameters of limestone specimen are shown in Table 1.

2.2. Principle of Coupled Static-Dynamic Loads. In this test, modified dynamic testing equipment in the State Key Laboratory of Mining Response and Disaster Prevention and Control in Deep Coal Mine was adopted to conduct the split tensile tests, as shown in Figure 1. SHPB equipment contained a high pressure air chamber and a bullet with spindle shape to reduce the dispersion effect and generate the half-sine wave, incident bar, transmitted bar, absorbed bar, and axial compression system. Two resistance strain gauges were mounted on the incident and transmitted bars to collect the incident, reflected, and transmitted waves. The limestone specimen was put in the radial direction between the incident and transmitted bars. The axial compression system can provide preload in the axial direction on the specimen. In the SHPB test, the preload was first applied on the specimen, and then the pressure air chamber was opened to make the bullet impact the incident bar; hence, a dynamic impact wave was generated, and the incident, reflected, and transmitted waves were collected from the strain gauges.

In dynamic split tensile tests, there are two key points to verify the availability of the test result [27]: (1) whether the crack initiation position started from the center point of the specimen and (2) whether the tensile crack was parallel to the loading direction. To verify the availability of data in Brazil split tests, Gomez et al. [28] conducted static and dynamic split tensile tests on the granite specimen according to the ASTM (American Society for Testing Materials) standard method, and the photoelastic images of the loading process was recorded using high-speed camera equipment. Test results indicated that the stress state under dynamic loading was similar to that under static loads, and similar test results were also observed by other investigations [29, 30] using RFPA software and DIC methods. Hence, the splitting tensile formula under static loads could extend to the dynamic tensile test, and the dynamic splitting tensile strength could be calculated using the elastic mechanics method, as shown in the following equation:

$$
\sigma_{\mathrm{d}}(t)=\frac{2 P(t)}{\pi D B}=-\frac{E A}{\pi D B}\left[\varepsilon_{\mathrm{I}}(t)-\varepsilon_{\mathrm{R}}(t)+\varepsilon_{\mathrm{T}}(t)\right],
$$

where $\sigma_{\mathrm{d}}(t)$ is the dynamic tensile stress of the rock specimen; $D$ and $B$ are the diameter and thickness of the rock specimen, respectively; $P(t)$ is the dynamic load in the radial direction; $E$ and $A$ are the elasticity modulus and crosssectional area of the compression bar, respectively; and $\varepsilon_{\mathrm{I}}(t)$, $\varepsilon_{\mathrm{R}}(t)$, and $\varepsilon_{\mathrm{T}}(t)$ are the incident strain, reflected strain, and transmitted strain, respectively.

The dynamic tensile strength $\left(\sigma_{\mathrm{d}}\right)$ was defined as the peak stress in the loading process in this research. In the coupled static and dynamic test, the specimen was maintained within the elastic range when the axial load was lower than its static strength. The stress-strain relationship obeyed Hooke's law; hence, the tensile stress of the disc specimen under the action of preload could be calculated as follows: 
TABLE 1: Basic static physical and mechanical parameters of limestone specimen.

\begin{tabular}{lcccccccc}
\hline \multicolumn{3}{c}{ Physical parameter } & \multicolumn{3}{c}{ Static mechanical parameters } & \multicolumn{3}{c}{ Mechanical parameters of splitting tension } \\
$\begin{array}{l}\text { Density } \\
\left(\mathrm{kg} \cdot \mathrm{m}^{-3}\right)\end{array}$ & $\begin{array}{c}\text { Longitudinal wave } \\
\text { velocity }\left(\mathrm{m} \cdot \mathrm{s}^{-1}\right)\end{array}$ & $\begin{array}{c}\text { Load rate } \\
\left(\mathrm{mm} \cdot \mathrm{s}^{-1}\right)\end{array}$ & $\begin{array}{c}\mathrm{UCS} \\
(\mathrm{MPa})\end{array}$ & $\begin{array}{c}\text { Static } \\
\text { modulus } \\
(\mathrm{GPa})\end{array}$ & $\begin{array}{c}\text { Poisson } \\
\text { ratio }\end{array}$ & $\begin{array}{c}\text { Loading rate } \\
\left(\mathrm{mm} \cdot \mathrm{s}^{-1}\right)\end{array}$ & $\begin{array}{c}\text { Tensile } \\
\text { strength } \\
(\mathrm{MPa})\end{array}$ & $\begin{array}{c}\text { Deformation } \\
\text { modulus }(\mathrm{GPa})\end{array}$ \\
\hline 2674 & 5004 & $2 \times 10^{-2}$ & 63.68 & 5.382 & 0.1515 & $2 \times 10^{-2}$ & 6.47 & 0.389 \\
\hline
\end{tabular}

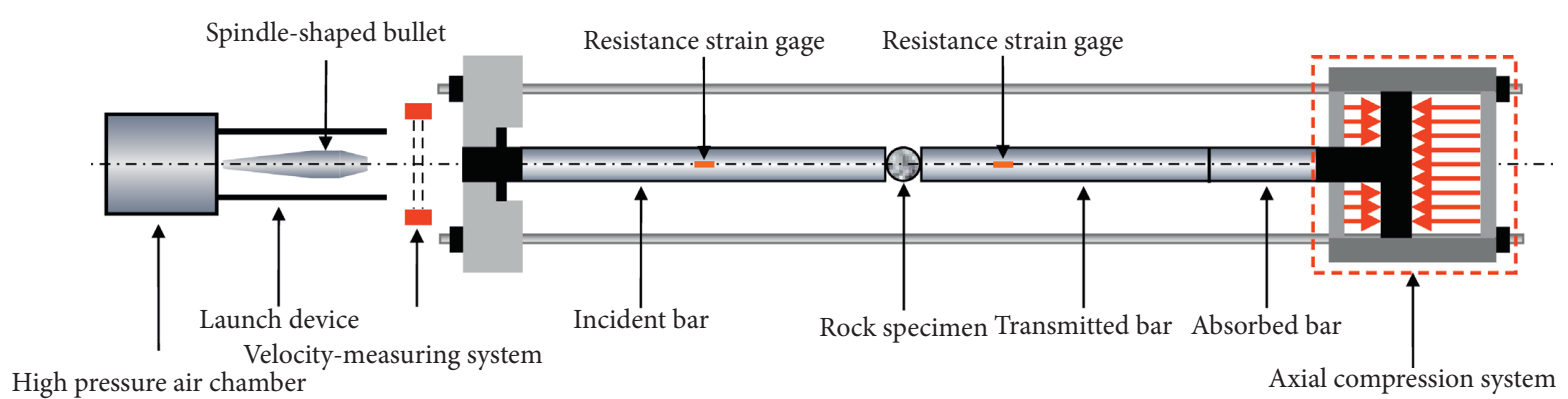

FIGURE 1: Coupled static and dynamic loading equipment for disk specimen.

$$
\sigma_{\mathrm{s}}=\frac{2 P_{\mathrm{s}}}{\pi D B}
$$

where $\sigma_{\mathrm{s}}$ is the tensile stress of the disc specimen, $\mathrm{MPa}$, and $P_{\mathrm{s}}$ is the preload.

Based on the abovementioned assumptions, both the stress and strain of the specimen under coupled loads satisfied the superposition principle; specifically, the stress and strain aroused from external loads were relatively independent. For the internal stress field and strain field of the specimen in the combined loading test, the total stress and strain could be obtained by superimposing the stress and strain under various loads by calculating the stress and strain, respectively. The stress analysis diagram under coupled static and dynamic loads is shown in Figure 2.

In Figure 2, $P$ is the loads in the radial direction, subscripts $s$ and $d$ are the static preload and dynamic loads, respectively, and subscripts 1 and 2 are the incident end and transmitted end, respectively.

If $\sigma_{\mathrm{s}}(x, y)$ and $\sigma_{\mathrm{d}}(x, y, t)$ were the stress field under static preload and dynamic load, respectively, the stress field $\sigma_{\text {sd }}(x$, $y, t)$ of the rock specimen under coupled static and dynamic loads is as follows:

$$
\sigma_{\text {sd }}(x, y, t)=\sigma_{\mathrm{s}}(x, y)+\sigma_{\mathrm{d}}(x, y, t) .
$$

It was observed that the stress field under static loads was relatively constant, which was time independent. Hence, the variation of the stress inside the specimen with time under coupled static and dynamic loads depended on the stress evolution of the specimen under dynamic impact. The internal stress field of the specimen at different times corresponded to that under the dynamic load. The difference lied in that the stress field under static load exists in the specimen before dynamic load. In the process of coupled static and dynamic loads, the stress in the specimen experienced three stages: disequilibrium, equilibrium, and disequilibrium. The internal stress of the specimen could reach equilibrium before failure attributes to a suitable shock loading waveform, and the stress distribution inside the specimen was consistent with the static load [31, 32].

Hence, the splitting tensile stress under coupled static and dynamic loads could be calculated using the static formula, and the stress states of the specimen at different times were superposed by static load stress field and dynamic load stress field, as shown in equation (4). The tensile strength of the specimen under coupled static and dynamic loads could be obtained by superposition of stress generated by static preloading and peak dynamic stress.

$$
\sigma_{\mathrm{ds}}(t)=\sigma_{\mathrm{s}}+\sigma_{\mathrm{d}}(t) \text {. }
$$

2.3. Analysis of Dynamic Force Balance. In the SHPB tensile test, stress equilibrium at both sides of the rock specimen required careful examination to guarantee the validation of data. Figure 3 shows the typical dynamic stresses under uniaxial and coupled static and dynamic states. It could be noticed that the transmitted wave basically coincides with the sum of the reflected and incident waves, and this phenomenon illustrated that the rock specimen was basically keep in stress equilibrium state during the loading process $[33,34]$.

\section{Splitting Tensile Test Results of Limestone Disc Specimen}

3.1. Test Results of Coupled Static and Dynamic Loads. Two test conditions were performed in this test: with preloading in the radial direction (coupled static and dynamic state) and without preloading in the radial direction (uniaxial state). The preloading was selected as $2 \mathrm{MPa}$, which was about $30 \%$ of the static tensile strength of the rock specimen. The test results are shown in Table 2.

3.2. Dynamic Tensile Load-Displacement Curves. The typical tensile load-displacement curves at uniaxial and coupled 


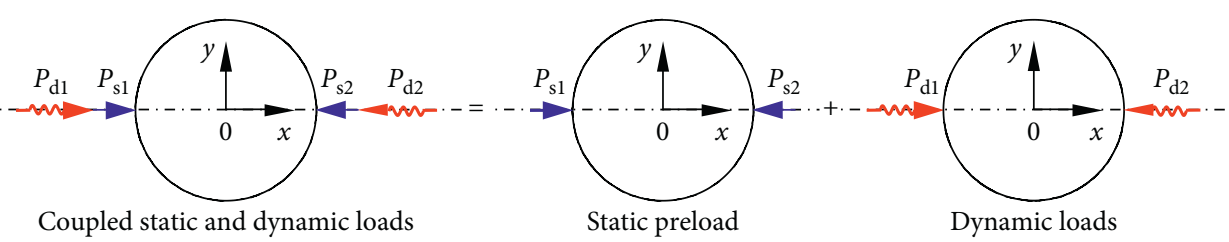

FIGURE 2: Stress analysis diagram of the disk specimen under coupled static and dynamic loading.

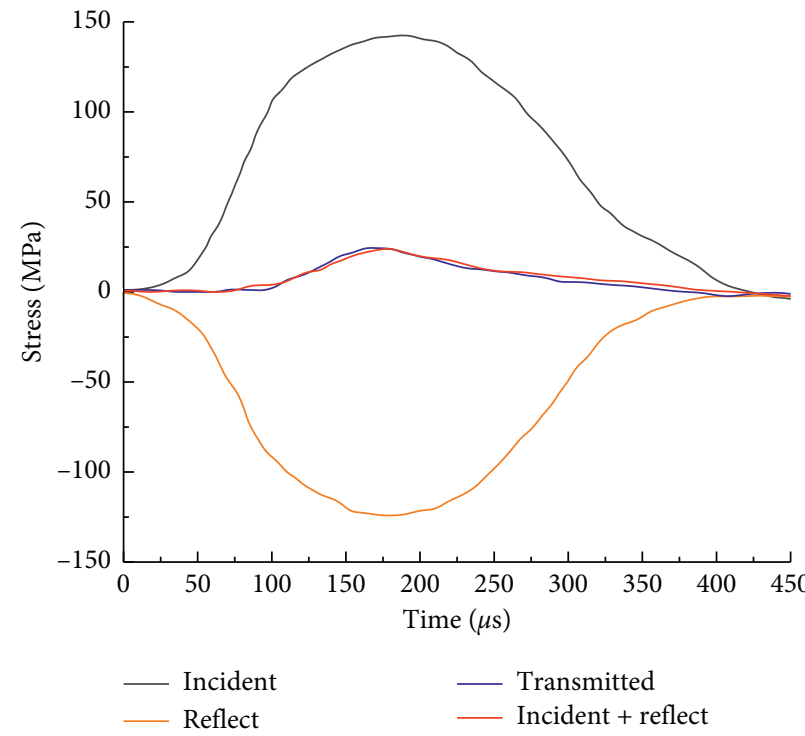

(a)

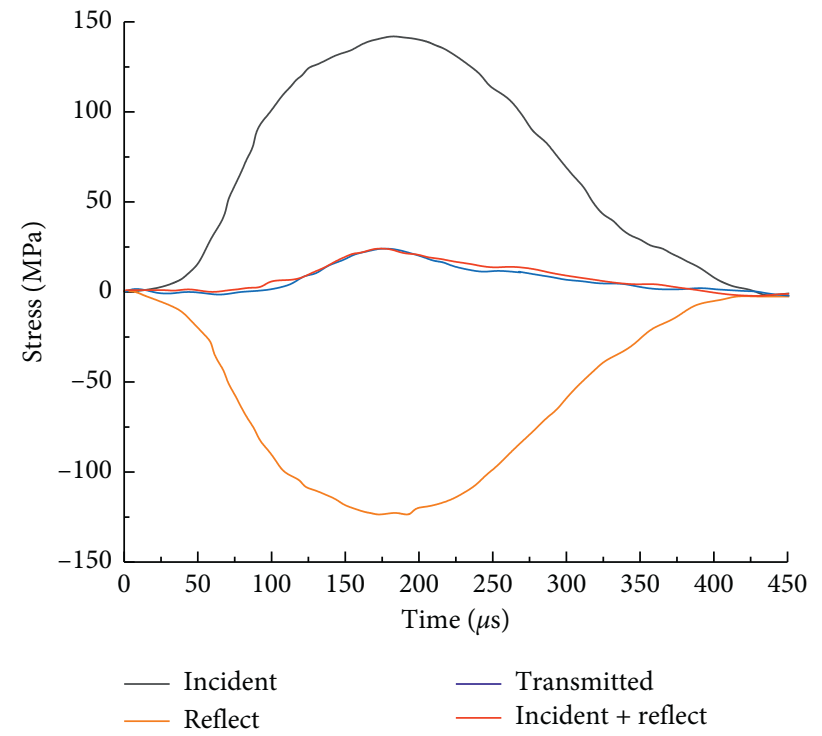

(b)

Figure 3: Typical dynamic stresses checked under uniaxial and coupled static and dynamic states. (a) Uniaxial state. (b) Coupled static and dynamic state.

static and dynamic (with $2 \mathrm{MPa}$ preloading) states obtained from SHPB tensile tests are shown in Figures 4 and 5, respectively.

From the abovementioned figures it could be noticed that in the SHPB tensile test, the characteristics of load-displacement curves under uniaxial and coupled static and dynamic states are similar, which could be divided into three stages. The first stage was elastic stage. The load-displacement increased rapidly, and the relationship between load and displacement exhibited linear relationship. The second stage was yield stage, the load-displacement curves exhibited fovea superior characteristic; moreover, this stage was short compared with the first one, and its slope decreased to 0 at peak stress. The third stage was failure stage. In this stage, the curves decreased sharply and the value of curve slope was negative.

The abovementioned figures show that under coupled static and dynamic state, both the dynamic tensile stress and strain in the radial direction increased with increasing strain rate and exhibited obvious strain rate effect. Under uniaxial state, the slopes at elastic stage showed no obvious changes, while it decreased with increasing strain rate under coupled static and dynamic state. By comparing Figures 3 and 4, it could be noticed that the dynamic peak stress under coupled static and dynamic state was lower than that under uniaxial state, while the strain increased with increasing strain rate.
3.3. Strain Rate Effect of Dynamic Tensile Strength. The relationship between strain rate and dynamic tensile strength under uniaxial and coupled static and dynamic states obtained from SHPB tensile tests is shown in Figure 6.

From Figure 6 it could be noticed that the dynamic tensile strengths were higher compared with that under the static state. Moreover, under uniaxial state, the values of dynamic tensile strength were 3.9 to 6.4 times higher compared with that under uniaxial state. In addition, the dynamic tensile strength power function increased with increasing average strain rate, and the fitting formula is as follows:

$$
\sigma_{\mathrm{ds}}=a \dot{\varepsilon}^{b}
$$

where $\sigma_{\mathrm{ds}}$ is the dynamic tensile strength of the rock specimen, $\dot{\varepsilon}$ is the strain rate in the radial direction, and $a$ and $b$ are the fitting parameters, which could be calculated by curve fitting, as shown in Table 3.

From Table 3, it was noticed that the fitting parameters between dynamic tensile strength and average strain rate under uniaxial and coupled static and dynamic states were 0.9473 and 0.9752 , respectively, showed better fitting degree. This phenomenon indicated that the dynamic tensile strength of the limestone specimen was strongly dependent on strain rate under two test conditions. 


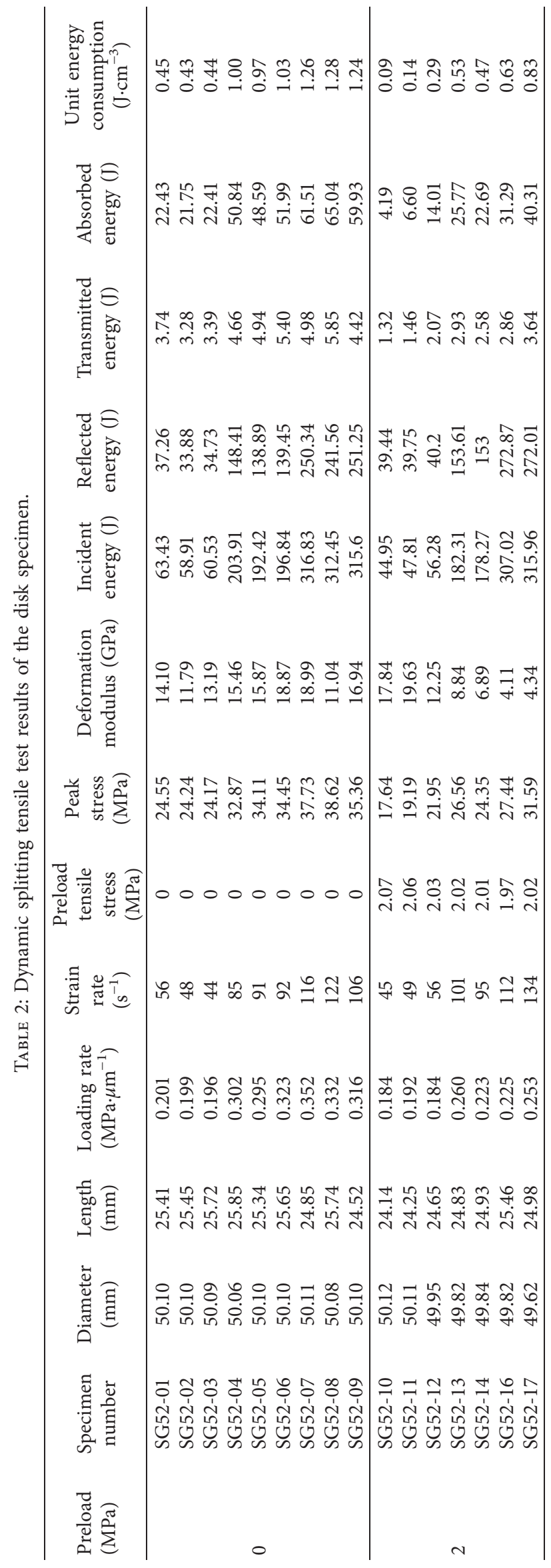




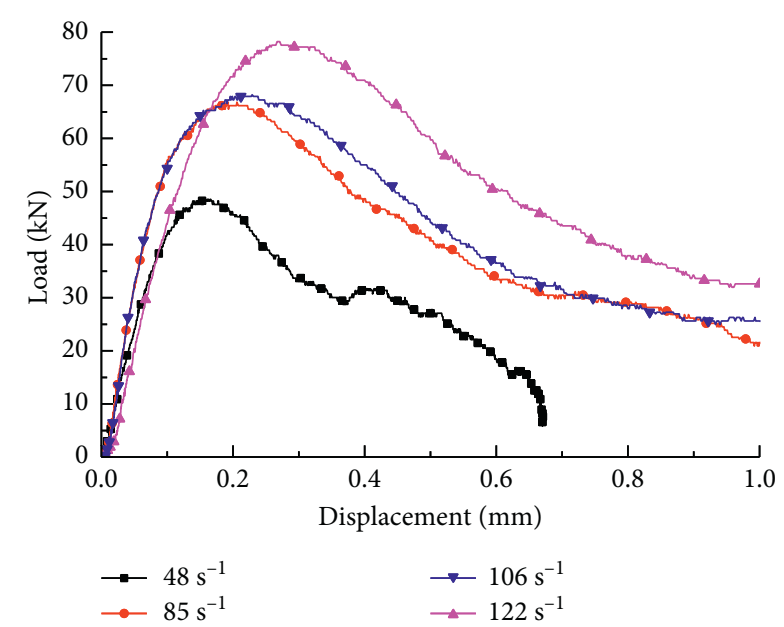

FIGURE 4: Dynamic splitting tensile load-displacement curves of the limestone disk specimen $\left(P_{\mathrm{s}}=0 \mathrm{MPa}\right)$.

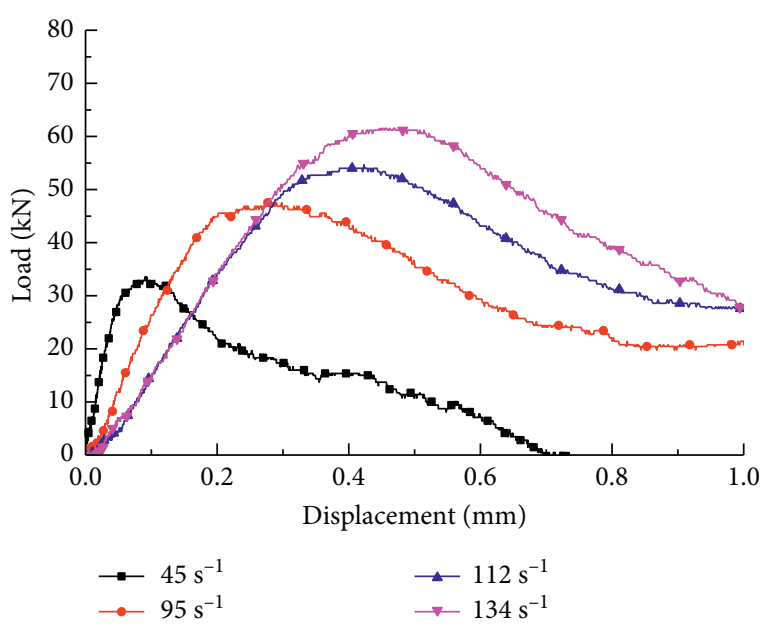

FIGURE 5: Dynamic splitting tensile load-displacement curves of the limestone disk specimen $\left(P_{\mathrm{s}}=2 \mathrm{MPa}\right)$.

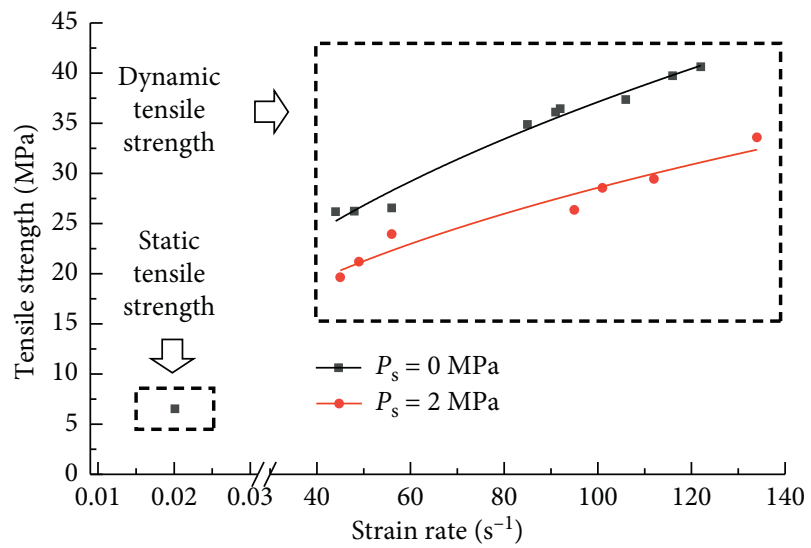

FIGURE 6: Dynamic splitting tensile stress-strain curves of the disk specimen.

Figure 6 shows that the dynamic tensile strength of the limestone specimen under coupled static and dynamic state was lower compared with that under the uniaxial state. This
TABLE 3: Fitting parameters between dynamic splitting tensile strength of the limestone disk specimen and average strain rate.

\begin{tabular}{lccc}
\hline Static preloading $(\mathrm{MPa})$ & $a$ & $b$ & Fitting parameters $\left(R^{2}\right)$ \\
\hline 0 & 4.2682 & 0.4696 & 0.9752 \\
2 & 4.1069 & 0.4208 & 0.9473 \\
\hline
\end{tabular}

phenomenon could be illustrated as follows: the static tensile strength of the limestone specimen was relatively low compared with its compressive strength; hence, the original disordered microcracks inside the specimen would develop to orderly direction and new cracks would generate under the action of static preload before impact loading. Those damages weakened the bearing capacity in the radial direction, leading to the decrease of dynamic tensile strength.

3.4. Strain Rate Effect of Dynamic Deformation Modulus. The dynamic deformation modulus was defined as the slope of the line from the origin to the point at which the stress was $50 \%$ peak stress on displacement-load curve, as shown in the following equation:

$$
E_{\mathrm{ds} 50}=\frac{\sigma_{\mathrm{sd} 50}}{\varepsilon_{\mathrm{sd} 50}}
$$

The relationship between strain rate and dynamic deformation modulus under uniaxial and coupled static and dynamic states obtained from this test is shown in Figure 7.

Figure 7 reveals that under the uniaxial state, the dynamic deformation modulus of the limestone specimen increased with increasing average strain rate and exhibited obvious rate dependence. This phenomenon was mainly caused by the deformation hysteresis of the rock specimen under dynamic impact loading [35]. However, the dynamic deformation modulus of limestone specimen decreased with increasing average strain rate under coupled static and dynamic state. The tensile strength of the specimen was low, and the radial preloading masked the disc specimen showed damage state before the action of dynamic load, and the crack inside the specimen extended rapidly under the impact load; hence, the deformation modulus of the specimen gradually decreased with the increase of the average strain rate.

3.5. Dynamic Failure Mode of Limestone Specimen. The failure modes of limestone specimens under different preloads and stress states were obtained, shown in Figure 8.

Figure 8 reveals that similar failure modes of limestone specimen were found under uniaxial state (without preload), and the main failure mode was split into two roughly equal semicylinders along the radial loading direction. In addition, the contact areas among the specimen, incident bar, and transmitted bar appeared as a local crushing phenomenon. The incident energy was relatively small at low strain rate. Therefore, the absorbed energy of the specimen was primarily used to the propagation of the main crack, and the specimen was split into two relatively complete parts. However, the incident energy was larger at high strain rate and part of the absorbed energy was used 


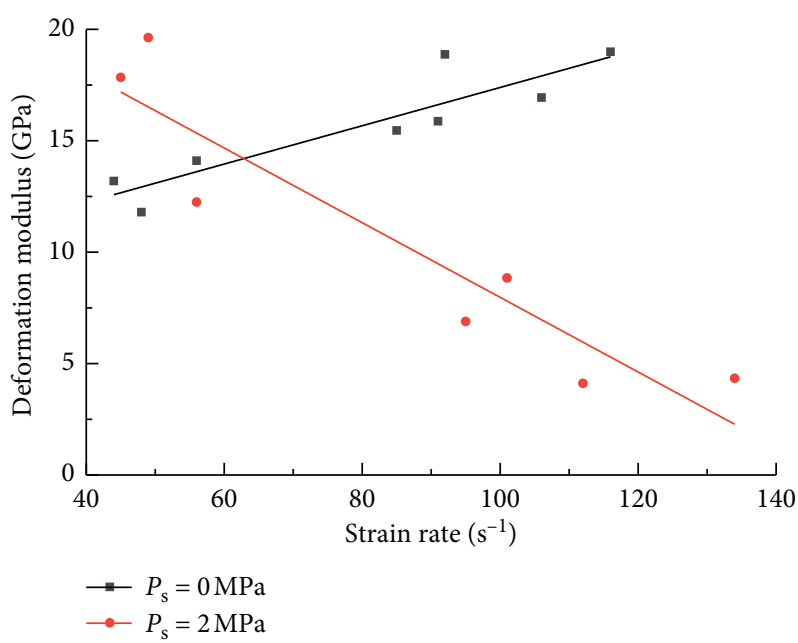

FIGURE 7: Relationship between dynamic deformation modulus and average strain rate.

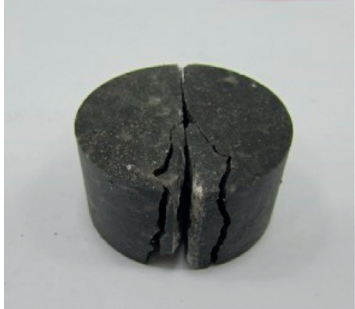

$48 s^{-1}$

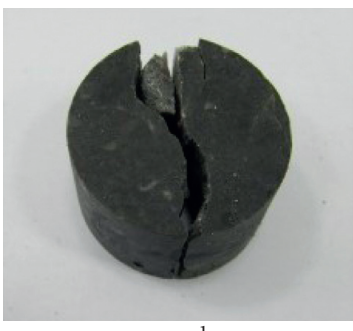

$45 \mathrm{~s}^{-1}$

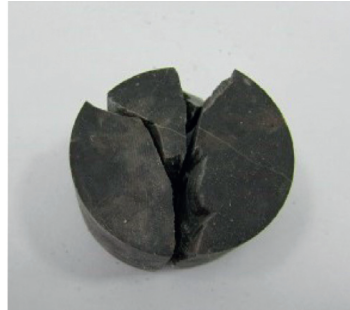

$85 \mathrm{~s}^{-1}$

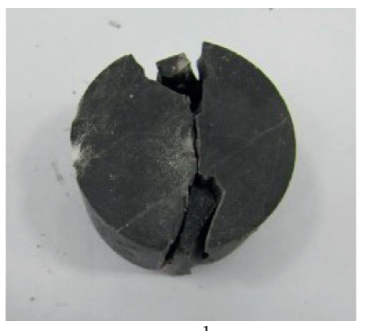

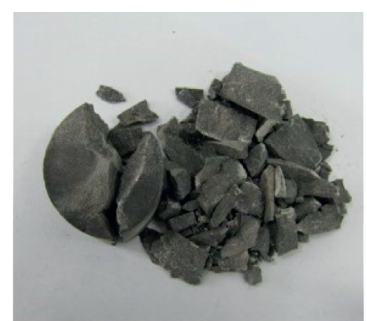

$106 \mathrm{~s}^{-1}$

(a)

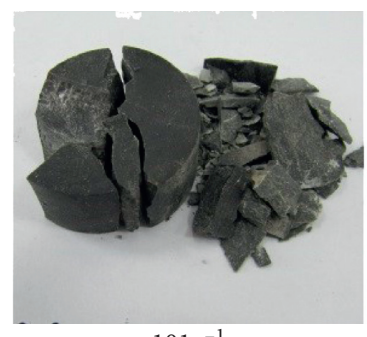

$101 \mathrm{~s}^{-1}$

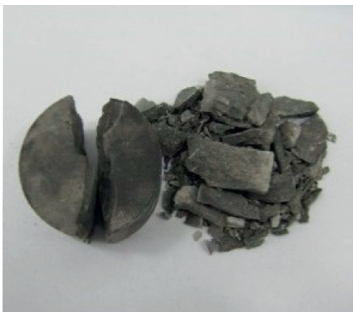

$122 \mathrm{~s}^{-1}$

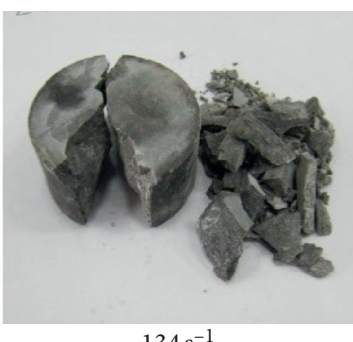

$134 \mathrm{~s}^{-1}$

(b)

Figure 8: Failure modes of limestone specimen under different strain rates. (a) Without preload $\left(P_{s}=0 \mathrm{MPa}\right)$. (b) With static preload $\left(P_{\mathrm{s}}=2 \mathrm{MPa}\right)$.

for the propagation of the main crack, and others were used for crushing the connect area between the specimen and bars.

Under coupled static and dynamic state, the failure mode of the limestone specimen was multiple cracks. Under the action of static preload in the radial direction, there existed lots of microcracks, and those microcracks developed into secondary cracks equivalent to the main cracks. With increasing impact loading, the pressure stresses at both sides of the specimen increased sharply, which was larger than the static compressive strength of the limestone specimen, resulting in the local crushing phenomenon.

\section{Energy Dissipation Analysis of Limestone Disc Specimen}

The energy dissipation of incident energy, reflected energy, and transmitted energy can be calculated using the common SHPB method [36]:

$$
\begin{aligned}
& W_{\mathrm{I}}(t)=E_{0} C_{0} A_{0} \int_{0}^{\tau} \varepsilon_{\mathrm{I}}^{2}(t) \mathrm{d} t, \\
& W_{\mathrm{R}}(t)=E_{0} C_{0} A_{0} \int_{0}^{\tau} \varepsilon_{\mathrm{R}}^{2}(t) \mathrm{d} t, \\
& W_{\mathrm{T}}(t)=E_{0} C_{0} A_{0} \int_{0}^{\tau} \varepsilon_{\mathrm{T}}^{2}(t) \mathrm{d} t,
\end{aligned}
$$


where $\left(W_{\mathrm{I}}\right),\left(W_{\mathrm{R}}\right),\left(W_{\mathrm{T}}\right)$ are the incident energy, reflected energy, and transmitted energy, respectively; $E_{0}, A_{0}$, and $C_{0}$ are Young's modulus, the cross-sectional area, the elastic wave speed of the bar, respectively; and $\tau$ is the duration time of the elastic wave.

Under coupled static and dynamic loads, in the process of applying axial static preload, a certain amount of elastic strain energy had been deposited inside the limestone specimen, which should be considered in the calculation method [37, 38].

4.1. Energy Variation Law of Limestone Specimen. The typical incident energy, reflected energy, and transmitted energy time curves under uniaxial and coupled static and dynamic states obtained from SHPB tensile tests are shown in Figure 9 and 10 , respectively.

It could be noticed that under uniaxial state, during the initial loading stage, both the incident energy and reflected energy increased with time, while the transmitted energy increased slightly and showed no obvious change. All the energy showed no obvious change from about $380 \mu \mathrm{s}$. During the whole loading process, the transmitted energy of the specimen was quite small and basically remained unchanged. The specimen was sandwiched in the radial direction between the incident bar and the transmission bar with a small contact surface. When the incident energy was transmitted to the end of the incident bar, most of the energy was turned to the reflection energy. Moreover, most of the energy through the specimen was absorbed by the specimen to form the absorption energy. Only a small part of the energy was transmitted into the transmission bar to form the transmitted energy. From Figure 10, it is observed that under coupled static and dynamic state, during the initial loading stage, the reflected energy was larger than the incident energy, while the absorbed energy of the specimen showed a negative value. This phenomenon was caused by the energy release of elastic energy generated by the static preload, and part of energy was transmitted to the incident bar.

Figure 11 shows the variation in reflected energy, transmitted energy, and absorbed energy with incident energy. Without static preload, both the reflect energy and absorbed energy increased with increasing incident energy and exhibited better linear relationship. However, under coupled static and dynamic loads, the reflected energy was significantly larger than that under uniaxial state, while the absorbed energy was smaller than that under the uniaxial state. The transmitted energy maintained stability, and the scopes were 1.32 to $3.64 \mathrm{~J}$ and 3.28 to $5.85 \mathrm{~J}$ for uniaxial and coupled static and dynamic states, respectively. Moreover, the transmitted energy under coupled static and dynamic state was lower than that under the uniaxial state. This phenomenon indicated that the incident energy showed little effect on the transmitted energy, and the transmitted energy was closely related to the failure mode.

4.2. Relationship between Absorbed Energy and Dynamic Tensile Strength. The relationship between absorbed energy

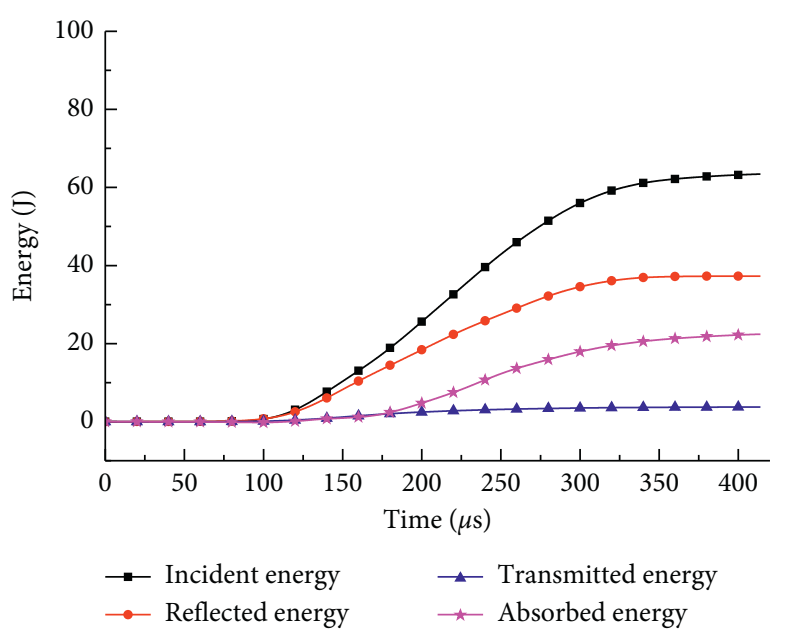

FIgURE 9: The energy history curve under the uniaxial state $\left(56 \mathrm{~s}^{-1}\right)$.

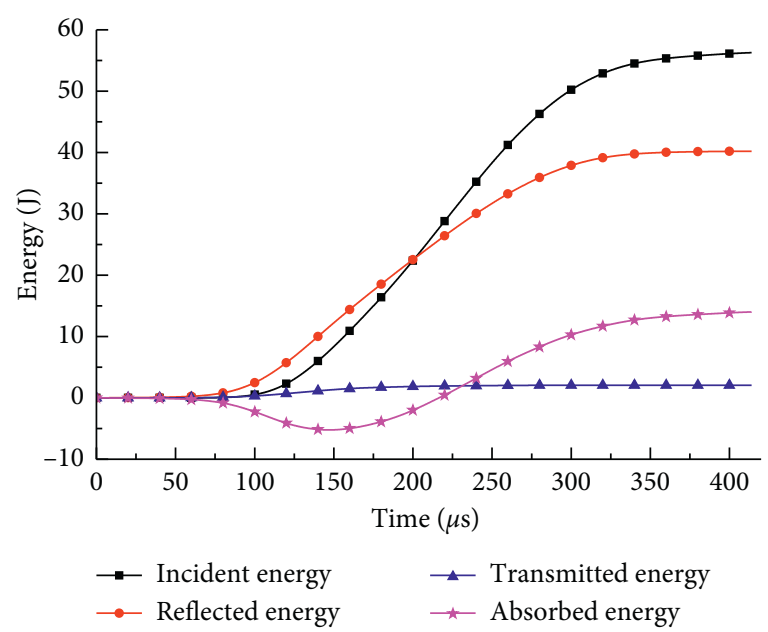

FIgURE 10: The energy history curve under the coupled static and dynamic state $\left(56 \mathrm{~s}^{-1}\right)$.

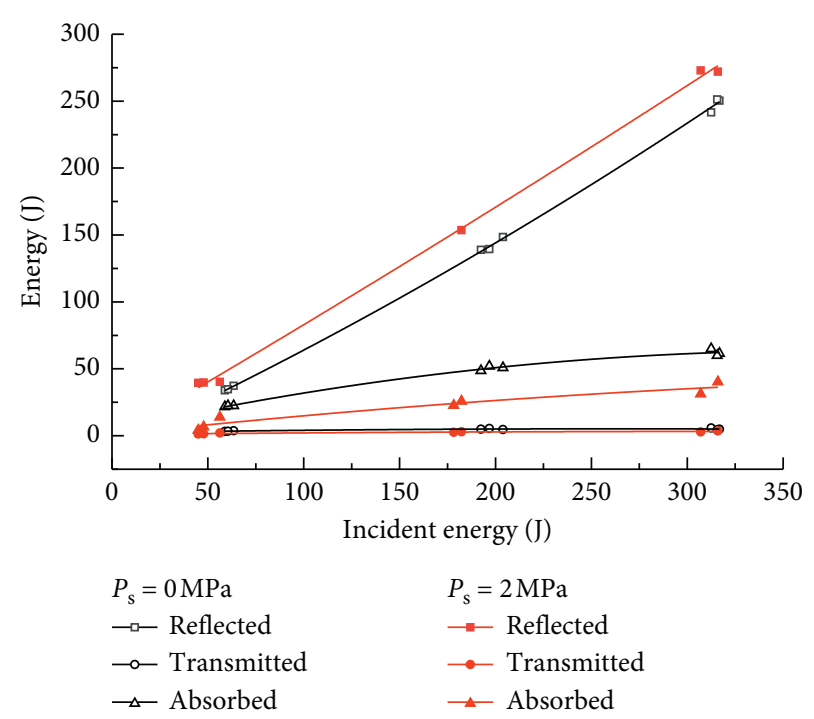

FIGURE 11: The variation in reflected energy, transmitted energy, and absorbed energy with incident energy. 


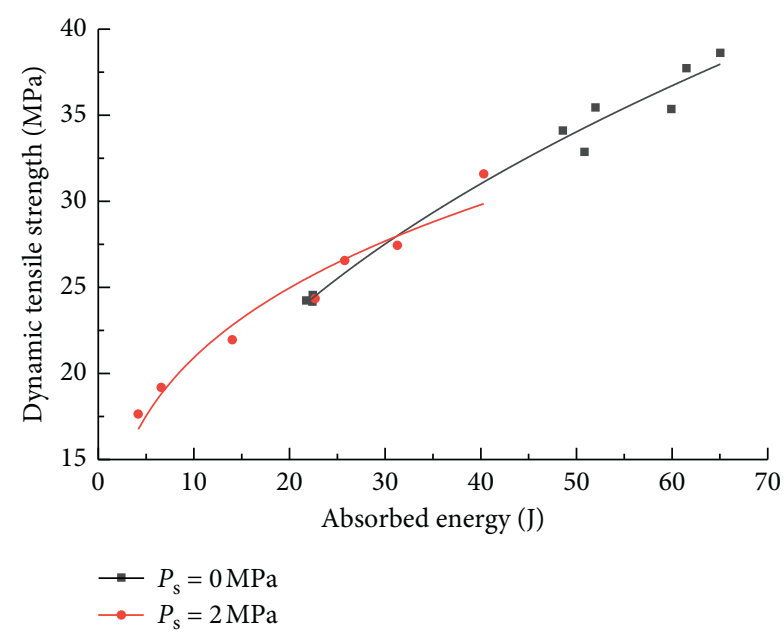

FIGURE 12: Relationship curve between dynamic tensile strength of the specimen and absorbed energy.

TABLE 4: Fitting parameters of dynamic tensile strength of the limestone specimen.

\begin{tabular}{lccc}
\hline Preload $(\mathrm{MPa})$ & $c$ & $d$ & $R^{2}$ \\
\hline 0 & 6.808 & 0.4102 & 0.9871 \\
2 & 13.911 & 0.2208 & 0.9569 \\
\hline
\end{tabular}

and dynamic tensile strength of the limestone specimen obtained from SHPB tensile tests is shown in Figure 12.

The dynamic tensile strength of the specimen increased approximately as a power function of the absorption energy, as shown in the following equation:

$$
\sigma_{\mathrm{ds}}=c W_{S}^{d},
$$

where $c$ and $d$ are the fitting parameters, respectively, which could be obtained using data fitting. Their values under different states are shown in Table 4.

Figure 12 shows that the absorbed energy increased with increasing dynamic tensile strength under uniaxial and coupled static and dynamic states. As the absorbed energy of the rock specimen increased, the energy transfer speed in the specimen increased, and the original microcracks in the specimen failed to crack or break through in time, leading to the deformation hysteresis of the specimen. Moreover, this hysteresis phenomenon would be more and more obvious with the increase of the absorbed energy of the specimen, resulting in the strengthening effect of the dynamic tensile strength of the specimen.

By comparing the relationship between absorbed energy and dynamic tensile strength, it could be noticed that the absorbed energy for reaching the tensile strength under uniaxial state was larger than that under coupled static and dynamic state. The static tensile strength of the limestone specimen was relatively low, and the specimen would damage under the action of preload, which weakened the tensile strength of the specimen; hence, less energy was need for reaching the failure state. Table 4 shows that the minimum value of fitting parameters between dynamic strength and absorbed energy was 0.9569 and showed a better correlation. This phenomenon indicated that the dynamic tensile strength of the limestone disk specimen was closely related to the absorption energy under two test conditions.

\section{Conclusions}

The dynamic splitting tensile tests under one-dimensional coupled static and dynamic state of limestone were tested using modified SHPB equipment. The dynamic mechanical property and energy dissipation characteristic were compared in this research. The main conclusions are as follows:

(1) The dynamic peak stress with preload was lower than that under the uniaxial state at the same strain rate. The dynamic tensile strength increased approximately as a power function with increasing average strain rate under two test states and exhibited an obvious strain rate effect. Different relationships between deformation modulus and average strain rate under two test states were found. Without preload, the deformation modulus increased with increasing strain rate; however, it decreased with increasing strain rate under coupled static and dynamic state, which was caused by the damage induced by the static preload in the radial direction.

(2) Under coupled static and dynamic state, during the initial loading stage, the reflected energy was larger than the incident energy, while the absorbed energy of the specimen showed negative value, which was caused by the release of the elastic energy generated by the static preload. Under coupled static and dynamic loads, the reflected energy was significantly larger than that under uniaxial state, while the absorbed energy was smaller than that under uniaxial state. Moreover, the transmitted energy under coupled static and dynamic state was lower than that under the uniaxial state.

\section{Data Availability}

The data used to support the findings of this study are available from the corresponding author upon request.

\section{Conflicts of Interest}

The authors declare that there are no conflicts of interest regarding the publication of this paper.

\section{Acknowledgments}

This research received financial supports from the National Natural Science Foundation of China (no. 51674008), Anhui Provincial Natural Science Foundation (no. 1808085ME134), Anhui Postdoctoral Science Foundation (no. 2015B058), and Doctoral Fund Project of Anhui University of Science and Technology (No. 11695). Thanks are due to the Engineering Research Center of Underground Mine Construction, Ministry of Education, and Anhui University of Science and Technology, State Key Laboratory of Mining Response and 
Disaster Prevention and Control in Deep Coal Mine, for providing the experiment conditions.

\section{References}

[1] Z. Y. Liao, J. B. Zhu, and C. A. Tang, "Numerical investigation of rock tensile strength determined by direct tension, Brazilian and three-point bending tests," International Journal of Rock Mechanics and Mining Sciences, vol. 115, pp. 21-32, 2019.

[2] P. Mpunzi, R. Masethe, M. Rizwan, and T. R. Stacey, "Enhancement of the tensile strengths of rock and shotcrete by thin spray-on liners," Tunnelling and Underground Space Technology, vol. 49, pp. 369-375, 2015.

[3] W. Yao, K. Xia, and X. Li, "Non-local failure theory and twoparameter tensile strength model for semi-circular bending tests of granitic rocks," International Journal of Rock Mechanics and Mining Sciences, vol. 110, pp. 9-18, 2018.

[4] International Society for Rock Mechanics (ISRM), "Suggested methods for determining tensile strength of rock materials," International Journal of Rock Mechanics and Mining Sciences and Geomechanics Abstracts, vol. 15, no. 1, pp. 99-103, 1978.

[5] The Professional Standards Compilation Group of People's Republic of China, MT 47-87 Methods for Determining the One-Way Tensile Strength Mechanical Properties of Coal and Rock, Coal Industry Publishing House, Beijing, China, 1987.

[6] The National Standards Compilation Group of People's Republic of China, GB/T 23561-2010 Methods for Determining the Physical and Mechanical Properties of Coal and Rock, Standards Press of China, Beijing, China, 2010.

[7] L. Luo, X. Li, M. Tao, and L. Dong, "Mechanical behavior of rock-shotcrete interface under static and dynamic tensile loads," Tunnelling and Underground Space Technology, vol. 65, pp. 215-224, 2017.

[8] A. Malik, T. Chakraborty, K. S. Rao, and D. Kumar, "Experiments to determine static and dynamic tensile strength of deccan trap rocks, India," Procedia Engineering, vol. 191, pp. 946-953, 2017.

[9] J. Shang, K. Duan, Y. Gui, K. Handley, and Z. Zhao, "Numerical investigation of the direct tensile behaviour of laminated and transversely isotropic rocks containing incipient bedding planes with different strengths," Computers and Geotechnics, vol. 104, pp. 373-388, 2018.

[10] Z. Zhou, X. Cai, D. Ma, L. Chen, S. Wang, and L. Tan, "Dynamic tensile properties of sandstone subjected to wetting and drying cycles," Construction and Building Materials, vol. 182, pp. 215-232, 2018.

[11] C. Liu, H. Deng, H. Zhao, and J. Zhang, "Effects of freeze-thaw treatment on the dynamic tensile strength of granite using the Brazilian test," Cold Regions Science and Technology, vol. 155, pp. 327-332, 2018.

[12] H.-B. Du, F. Dai, Y. Xu, Y. Liu, and H.-N. Xu, "Numerical investigation on the dynamic strength and failure behavior of rocks under hydrostatic confinement in SHPB testing," International Journal of Rock Mechanics and Mining Sciences, vol. 108, pp. 43-57, 2018.

[13] K. Xia, W. Yao, and B. Wu, "Dynamic rock tensile strengths of Laurentian granite: experimental observation and micromechanical model," Journal of Rock Mechanics and Geotechnical Engineering, vol. 9, no. 1, pp. 116-124, 2017.

[14] X. Si, F. Gong, X. Li, S. Wang, and S. Luo, "Dynamic MohrCoulomb and Hoek-Brown strength criteria of sandstone at high strain rates," International Journal of Rock Mechanics and Mining Sciences, vol. 115, pp. 48-59, 2019.
[15] Q. Jiang, F. Yan, J. Wu, Q. Fan, S. Li, and D. Xu, "Grading opening and shearing deformation of deep outward-dip shear belts inside high slope: a case study," Engineering Geology, vol. 250, pp. 113-129, 2019.

[16] Q. Jiang, G. Su, X.-T. Feng, G. Chen, M.-Z. Zhang, and C. Liu, "Excavation optimization and stability analysis for large underground caverns under high geostress: a case study of the Chinese laxiwa project," Rock Mechanics and Rock Engineering, vol. 52, no. 3, pp. 895-915, 2019.

[17] F. Q. Gong, L. Zhang, and S. Y. Wang, "Loading rate effect of rock material with the direct tensile and three Brazilian disc tests," Advances in Civil Engineering, vol. 2019, Article ID 6260351, 8 pages, 2019.

[18] L. Song and F. Q. Gong, "Experimental and numerical analyses of the rational loading waveform in SHPB test for rock materials," Advances in Civil Engineering, vol. 2018, Article ID 3967643, 13 pages, 2018.

[19] D. Ai, Y. Zhao, Q. Wang, and C. Li, "Experimental and numerical investigation of crack propagation and dynamic properties of rock in SHPB indirect tension test," International Journal of Impact Engineering, vol. 126, pp. 135-146, 2019.

[20] B. B. Wu, R. Chen, and K. W. Xia, "Dynamic tensile failure of rocks under static pre-tension," International Journal of Rock Mechanics \& Mining Sciences, vol. 80, pp. 12-18, 2015.

[21] Y. Deng, M. Chen, Y. Jin, and D. Zou, "Theoretical analysis and experimental research on the energy dissipation of rock crushing based on fractal theory," Journal of Natural Gas Science and Engineering, vol. 33, pp. 231-239, 2016.

[22] F. Dai, K. Xia, J. P. Zuo, R. Zhang, and N. W. Xu, "Static and dynamic flexural strength anisotropy of Barre granite," Rock Mechanics and Rock Engineering, vol. 46, no. 6, pp. 1589-1602, 2013.

[23] F. Q. Gong and G. F. Zhao, "Dynamic indirect tensile strength of sandstone under different loading rates," Rock Mechanics \& Rock Engineering, vol. 47, no. 6, pp. 2271-2278, 2014.

[24] F.-Q. Gong, X.-F. Si, X.-B. Li, and S.-Y. Wang, "Dynamic triaxial compression tests on sandstone at high strain rates and low confining pressures with split Hopkinson pressure bar," International Journal of Rock Mechanics and Mining Sciences, vol. 113, pp. 211-219, 2019.

[25] J. C. Li, N. N. Li, H. B. Li, and J. Zhao, "An SHPB test study on wave propagation across rock masses with different contact area ratios of joint," International Journal of Impact Engineering, vol. 105, pp. 109-116, 2017.

[26] K. W. Xia and W. Yao, "Dynamic rock tests using split Hopkinson (Kolsky) bar system-a review," Journal of Rock Mechanics and Geotechnical Engineering, vol. 7, pp. 25-79, 2015.

[27] M. Li, L. Qiao, and Q. W. Li, "Energy dissipation of rock specimens under high strain rate with single joint in SHPB tensile tests," Chinese Journal of Geotechnical Engineering, vol. 39, no. 7, pp. 1336-1343, 2017.

[28] J. T. Gomez, A. Shukla, and A. Sharma, "Static and dynamic behavior of concrete and granite in tension with damage," Theoretical and Applied Fracture Mechanics, vol. 36, no. 1, pp. 37-49, 2001.

[29] W. C. Zhu, Y. Bai, X. B. Li, and L. L. Niu, "Numerical simulation on rock failure under combined static and dynamic loading during SHPB tests," International Journal of Impact Engineering, vol. 49, pp. 142-157, 2012.

[30] J. J. Chen, Study on the Dynamic Mechanical Properties of Brittle Materials by High-Speed DIC, Beijing Institute of Technology, Beijing, China, 2014. 
[31] M. Z. Sheikh, Z. Wang, B. Du et al., "Static and dynamic Brazilian disk tests for mechanical characterization of annealed and chemically strengthened glass," Ceramics International, vol. 45, no. 6, pp. 7931-7944, 2019.

[32] Q. H. Wu, X. B. Li, L. Weng et al., "Experimental investigation of the dynamic response of prestressed rockbolt by using an SHPB-based rockbolt test system," Tunnelling and Underground Space Technology, vol. 93, Article ID 103088, 2019.

[33] F. Dai, S. Huang, K. Xia, and Z. Tan, "Some fundamental issues in dynamic compression and tension tests of rocks using split Hopkinson pressure bar," Rock Mechanics and Rock Engineering, vol. 43, no. 6, pp. 657-666, 2010.

[34] H. B. Du, F. Dai, Y. Xu et al., "Mechanical responses and failure mechanism of hydrostatically pressurized rocks under combined compression-shear impacting," International Journal of Mechanical Sciences, vol. 165, Article ID 105219, 2020.

[35] W. Li, H. P. Xie, and Q. Z. Wang, "An experimental study for the dynamic split tension of marble disc using SHPB," Explosion and Shock Waves, vol. 26, no. 1, pp. 12-20, 2006.

[36] Q. Ping, Q. Y. Ma, and P. Yuan, "Energy dissipation analysis of stone specimens in SHPB tensile test," Journal of Mining \& Safety Engineering, vol. 30, no. 3, pp. 401-407, 2013.

[37] D. D. Ma, Q. Y. Ma, Z. M. Yao et al., "Static-dynamic coupling mechanical properties and constitutive model of artificial frozen silty clay under triaxial compression," Cold Regions Science and Techology, vol. 167, Article ID 102858, 2019.

[38] W. Wang, S. W. Zhang, and H. M. Liu, "Analysis of the dynamic impact mechanical characteristic of prestressed saturated fractured coal and rock," Advances in Civil Engineering, vol. 2019, Article ID 9196263, 10 pages, 2019. 